\title{
CORRECTION TO THE PAPER "FLUCTUATIONS OF \\ THE RADIATION FROM A GAS LASER HAVING A \\ RING CAVITY"*
}

\section{L. Bershtein}

In my paper titled as above, which was published in Issue No. 2 of the present year (p. 252), there is an error: Eq. (26) contains an incorrect expression for the splitting frequency $\Omega_{0}$ derived from Eq. (22). In order to find the small correction to $\Omega_{0}$ that is caused by the effect of partial entrainment, one cannot use the approximation adopted in deriving (22). Correct calculation yielded the following approximate expression for $\Omega_{0}$ :

$$
\Omega_{0} \approx \delta-\frac{B^{2}}{2 \delta}-\frac{1}{2} \frac{\alpha}{p^{2}(1-n)^{2}+\delta^{2}}\left\{p(1-n)\left(r_{1}^{2}-r_{2}^{2}\right)-\delta\left[2 r_{1} r_{2} \sin 2 \varepsilon+\alpha\left(r_{1}^{2}+r_{2}^{2}-2 r_{1} r_{2} \cos 2 \varepsilon\right)\right]\right\} .
$$

The approximation adopted in (22) did not affect the results of the calculations of the fluctuation processes.

I thank V.A. Markelov for indicating the error.

\footnotetext{
*Issue No. 2, 1971.
} 1971.

Translated from Izvestiya Vysshikh Uchebnykh Zavedenii, Radiofizika, Vol. 14, No. 5, p. 796, May,

- 1973 Consultants Bureau, a division of Plenum Publishing Corporation, 227 West 17th Street, New York, N. Y. 10011. All rights reserved. This article cannot be reproduced for any purpose whatsoever without permission of the publisher. A copy of this article is available from the publisher for $\$ 15.00$. 